\title{
FinTech Innovations in Digital Banking
}

\author{
Vivek Dubey \\ Insights \& Data \\ Capgemini \\ Glasgow, United Kingdom
}

\begin{abstract}
Recently, Fintech technologies have taken shape in digital banking across the globe. These technologies include artificial intelligence, augmented reality, and blockchain technology. Currently, AR technology is having a vibrational impact in numerous industry sectors. From being deployed in healthcare, oil and gas construction, and retail as well as manufacturing, AR technologies are currently deployed to increase process efficiency, reduce costs and bring about a broad range of commercial benefits. Artificial intelligence is the rising star in the world of technology. Now, there is something we need to understand about artificial intelligence because it is currently one of the hot topics on social media and is being discussed by millions of people around the world. The use of blockchain was decisively made in 2018 when the technology finally shifted from margins to the mainstream in multiple vital industries such as healthcare, government, insurance, supply chain management, and of course, finance. According to statistics, a sum of $\$ 1.3$ billion was globally invested in FinTech projects based on blockchain innovation. Progressive financial organizations have also increased their spending on internal bank technologies, especially the ones powered by the permanent ledgers. Therefore, this paper discusses the role of Artificial Intelligence, Augmented Reality, and Blockchain in Digital Banking.
\end{abstract}

Key words: Artificial Intelligence, Augmented Reality, Blockchain, banking, technology, digital

\section{INTRODUCTION}

Banking as an activity continues to take root in the world. The banking sector has fully convalesced from the financial predicament, and a significant boom can be observed compared to the past decade. However, the meaning of a significant boom is not tied to banks operating the usual way, not experiencing changes that disrupt the activities (Bhuvana, Thirumagal, and Vasantha, 2016). New technologies in the finance sector cause these changes.Delivery of financial products that perfectly satisfy the current expectations of customers is one way through which companies under FinTech are steering violent rivalry for the market from the young population.

Massive growth is being witnessed by businesses, which have molded their products according to the above attributes. Companies dealing in accessible transfer payment selections at a low cost have created a market capitalization worth $\$ 600$ billion. At present, Startups by FinTech dominate these positions (Bhuvana, Thirumagal, and Vasantha, 2016).Additionally, the old financial institutions, which do not improve their innovation but choose to stay in the old ways, end up losing on the market from the customers in the new generation, mainly evolving markets. The economic foundations are unshakable. The impact of technology on banking activities will continue to strengthen as the robustness and accessibility of technology are increasing with time (Degbelo et al., 2016). It is possible that observing the current trends in technology in financial services is useful to predict the future needs of your business. There are several innovations mentioned that cover the role of Artificial Intelligence, Augmented Reality, and Blockchain in Digital Banking.

\section{INVESTING OPPORTUNITIES ARE BEING TAKEN UP BY DIGITAL CURRENCIES.}

Prices of the bitcoin may have continuously increased this year, but this has did not affect the demand and interest in the coin for customers (these have remained high). What is more appealing are the institutional investors who are also entering the trading space of cryptocurrency.

A report from Bloomberg says that Hedge funds have been regularly purchasing the digital coins worth $\$ 100,000$ and more not leaving out other institutional buyers (Degbelo et al., 2016). The standard market is approximated to be in the range $\$ 250$ million - \$30billion in daily trade as in April 2018. No doubt, the number of institutional investors who are willing to occupy the crypto-trading space is continuously increasing. These investors prepare to probably start new services in the finance sector applications, especially operations in the digital coins.

Goldman Sachs Group became the first bank to give a trading product in the bitcoin to its customers. This was after taking the opposite side as an ex vocal detractor of digital money.

Recently, Gold Sachs Group has involved a sample of its clients in studying their latest technology in finance. This is a resolution facilitating the exchange of non-deliverable futures contracts using the bitcoin. However, currently, the same company cannot store assets of cryptocurrencies for its customers despite the high plea for this service (Pilkington, 2018)

As a fact, the demand by individuals to purchase and save the digital coin has significantly increased over the last year, and this trend is expected to keep up in 2019. This is an outstanding opportunity for competitive institutions to enter the crypto- space and produce in demand-operations to all types of customers (Pilkington, 2018).

There are many more companies in the competition to get customers in digital trade. NASDAQ, too, is seeking licensing from Future Trading Commission (CFTC) and commodities to make it a future market operator of cryptocurrency. 


\section{INCREASE IN MOBILE PAYMENTS.}

Even though the start was slow, mobile payments are becoming more and more popular, especially in the young population. Results from Visa's research reveal that 65 out every 100 individuals aged 18-34years have used mobile disbursements online to make transactions. The sum of users of mobile payments reduces to $42 \%$ with an expansion in the range. In addition to this, approximately half of payments by having been being done face-face on Android pay and mobile devices in the last year. In addition to these statistics, smartphones and tablets are used by more than half $(57 \%)$ of the millennials to transfer cash to family and friends (Bhuvana et al., 2016).

The region of Asia and the Pacific is the leading adaptor of payments using banking solutions and mobile devices. The new banking trends and being shaped by shifting demands and behaviors of consumers.

- 77 out of 100 consumers in china show interest in optional payment and banking solutions.

- 61 out of 100 Chinese millennials also report that they would instead practice accessing financial and banking services using IoT gadgets.

- Only 19\% of bankers in the APAC region do not trust that consumers currently do not need a one entry point to meet their financial requirements wholly and are probably already starting such projects (Bhuvana et al., 2016).

The preference of phones for keeping personal financial information and conducting daily payment maneuvers is increasing continuously. Many customers are of the view that online wallet services are more secure compared to hard copy bank cards. With this, should banks be threatened by online wallet services? Contrary to this, the increased preference for online wallet services by consumers can aid the growth of more financial services. Foremost, your bank can decrease fees on interchange using debit/credit cards by giving a custom online wallet solution (Bhuvana et al., 2016). Even a reduction of $2 \%$ in these fees is good enough.

The second advantage is in the offer of a new way of communication to reach customers online. Online wallet services, if combined with unlimited accessibility, can generate revenue for one's business. One can mobilize users and market the service by collecting and analyzing data about users and sending them appropriate messages at the right time. An example is adding a credit line to clients who have timed recurring payments but do not possess enough credit for instant payments (Bhuvana et al., 2016).

More so, the new list of information can help to improve the instant detection of fraud and create more robust policies on security for existing and new customers in place of following new regulations executed by additional service providers. The persistence of Neo banks as the newest innovation in the sector of banking is expected to last in only 2019, mainly in markets in Europe.

\section{DIGITAL NEO BANKS PRESENTS ADDITIONAL} COMPETITION

The persistence of Neo banks as the latest trend in the banking sector is expected to last in only 2019, mainly in markets ofEurope.Entirely online, low costs on operations and no branches, these market disruptors attract customers through affordable prices, unchallengeable CX, and modern gen functionality which include:

- Free of charge credit cards(Nubank);

- Luring rates on foreign exchange;

- Cards that support multiple currencies;

- products on cryptocurrency trade(Revolut);

- Insurance services, and others.

According to the views of $\mathrm{CB}$, crypto trade unaccompanied is handling more than $\$ 1.8$ billion of monthly overheads through 28 states in Europe and is expanding to 3million accounts owned by customers.Coming up markets presently reflect the most significant fresh opportunity for growth of online banking creation with extraordinary mobile acceptance rates and vast unbanked population. Customary banks ought totake note and cogitate entering the field before startups by FinTech overtaking them. The following are a few more critical changes in banking that are worth observing as recommended by Deloitte:

- Customers of banking have more strong emotional contact with technology brands such as Amazon, Apple, and Google than they do with their banks. The latter issue is a partial explanation of the increasing adoption and popularity of using mobile phones for payments. Banks should observe the means through which these brands have made it out to fit the physical and online experiences and imitate those.

- The segment of personal loans is a ready field for stable innovation in banking. The products of FinTech now make 36\% of individual loans in the US measured by dollar sums. Better online products could enable banks to lure back an expanding segment of digital lender answers for college dues.

- Collaboration in place of competition with new banks; this is a strategy that could considerably improve productivity in more prominent financial institutions. Instead of creating a neo online solution from first principles, banks could import some operations to their online partners.

Contrary wise, Consumers are eager to intensify usage of a branch when offered the features matching their needs but are not yet set to leave the branch altogether:

The newest technology in banking should be aimed at refining omnichannel $\mathrm{CX}$, instead of oscillating in the direction of either physical or online stance of things.

\section{A Competitive Advantage can be attained with the aid of cognitive banking.}

Cognitive computing is a new technology in business that could aid old-style banks to outcompete neorivals in the field of grander customer experience. Cognitive banking is a broader term for programs with the 
ability to simulate the thinking of humans with the aid of technology, which includes sound recognition, machine learning(ML), and natural language processing (NLP), among others. A combination of one's immediate solutions to banking analytics with knowledgeable assistants gives him/her the ability to analyze and divide his customer base with an increase in precision and creation of real personalized experiences per user.

\section{CUSTOMER SUPPORT FUELED BY ML}

Self-optimization can be done by smart systems with time and offer personalized customer support basing on their past usage. Wells Fargo studied a Facebook Messanger Chabot driven by Artificial intelligence (AI) early this year(Aazhvaar, 2019). The Chatbot could provide a broad line of assistance to users, for example, help with passwords of information about the account. With the aid of the technology of Artificial Intelligence, the researchers were able to structure another medium for customers to access essential information in the format of a conversation hastily. This is possible on a platform where they commonly log in and in place of browsing through many pages on the web or availing support tickets.

\section{AI DRIVES INVESTMENT}

The approximate sum of assets managed by Roboadvisors was the US $\$ 397,972$ million in late 2018. From the view of customers, the services offered by these products include:

- Better accountability in terms of investment alternatives and strategies

- Increased availability through minimum charges and the capability to invest at any amount every month

- Luring mobile and Web User Interfaces (UI's) that make products readily accessible and instinctive to explore, different from most old-style tools of investment tailored to satisfy experts rather than starters (Aazhvaar, 2019).

- The application of exchange-traded funds (ETFs) to create various portfolios

- A match between the increasing demand for the passive option of investment

Recently, an AI-powered contract intelligence platform (COIN) was deployed by JPMorgan Chase and is observed to have avoided physical labor work by 360,000 hours.

The performance of AI systems is approximated by McKinsey to be $10-25 \%$ across bank functions in the coming few years. However, this opportunity can be unlocked by banks taking a proactive side in innovating new procedures (Aazhvaar, 2019). These procedures should be able to suit automated performance instead of using $\mathrm{AI}$ as an alternative to a business value that is already low. Unlocking this opportunity also requires financial institutions to increase their in-door abilities for aiding the neo method of functioning and founding partnerships with a dealer in possession of particularterritory expertise in the industry of financial technology.

\section{Better optimization of risk}

The specialized advantage of systems fueled by AI is their ability to operate independently by gathering more information about several threats to security and more speed and greater confidence in responding (Shivkumar and Nihaal, 2017). The speed of these systems in analyzing data doubles human specialist ability, checking repetitive trends, realizing the correlation between different points in different data sets, and bringing out new views that can aid in ensuring securing without affecting CX.

Intelligent detection of payment fraud

Detection of payment fraud using "intelligent" means is by far the most significant AI trend. Computer programs have become increasingly more efficient in spotting out of rhythm behaviors and market abuse compared to humans. The outstanding appeal is that they can detect fraud in action for many accounts. MasterCard, as among the earliest adopters of AI-driven fraud management, has managed to reduce the number of occurrences of false declines faced by customers by 80 out of 100 cases (Shivkumar and Nihaal, 2017).

\section{BLOCKCHAIN PEER TO PEER LENDING}

By 2025, the global P2P lending is predicted to rise to 1 trillion dollars, dominated by numerous favored Fin-Tech startups like Lendoit, Circle, and others. This will only be possible if banks develop more innovative financial services to address the more, faster, and better streamlines lending process (Shah \& Jani, 2018). A significant role is played by Blockchain technology in this particular case since it is the final candidate for simplifying the diligence process. All the financial data of customers can be recorded and at the same time, stored on a fixed ledger. This gives the lending institution a real-time and complete view of the affairs of the applicants, such as outstanding details of inflows, outflows and bills, full transaction history, and so many others (Shah \& Jani, 2018). With the availability of such data, lending decisions are made strategically in the shortest time possible.

Additionally, the settlement process can be governed by smart contracts and as well as automate the implementation of the lending terms. The use of Blockchain technology also makes it easy to make borrowing/lending transactions and enables higher data visibility for investors, regulators, and auditors. Recently, ING and Credit Suisse became the pioneers for implementing the very first live securities trade on the platform of the blockchain (Baruri, 2016). They swapped EUR 25 million worth of very high-quality liquid assets.

\section{BLOCKCHAIN DIGITIZES SUPPLY CHAIN AND SHIPMENTS}

In business, one of the benefits of using blockchain technology is its ability to provide more transparency about the movement of the products through supply chain and shipments. Once the information is entered into the digital ledger, no individual can edit it. More so, there is ultimately no need for businesses to worry about the tampering of potential records. 
Furthermore, all the parties relevant in a given transaction can track the shipments and as well as help all members involved in the supply chain. In 2018, Maersk and IBM formed a team accurately to establish a blockchain platform for trade worldwide. IBM notes the costs of global trade an approximation of $\$ 1.8$ trillion per year, and that the savings made in more efficient processes could cut off approximately $10 \%$ of that (Shah \& Jani, 2018).

Recently, LogChain, an Israeli startup, completed its first multinational maritime shipment with the use of end-to-end blockchain technology. Reports indicated that this method decreased shipping costs by $7 \%$ and allowed the required documentation time to take just minutes rather than a familiar couple of weeks. This is accounted for the use of smart contracts in LogChain that maintains all members in the supply chain in the loop (Baruri, 2016). These are a few of the numerous examples that indicate how blockchain streamlines shipments and supply chains by digitizing them.

\section{BANKS ALSO USE BLOCKCHAIN FOR VARIOUS PURPOSES}

In a survey carried out in 2017 about Americans' banking habits, it was reported that the majority of the Americans preferred using digital methods, with most of them choosing to bank through mobile phone and computer platforms. Only a quarter of the participants chose to use either bank branches or ATMs. Currently, banks are becoming more digitized because of the blockchain (Shah \& Jani, 2018).

\section{Blockchain and AI are used for signing current business contracts}

Practically, even the best intentions in any business often do not get far without the signing of contracts. The creation of contracts by businesses indicates that they may make transactions for weeks, months, or years (Baruri, 2016). However, the rate at which the business world is growing is very fast that the contracts can quickly become out of date. It is anticipated that very soon, blockchain and AI will be used together to provide updated contracts. Already, blockchain manages self-executing smart contracts (Shah \& Jani, 2018).

AI is often brought into the picture if some parts of the contracts show fixed terms and aspects that may alter automatically due to changes in the business environment. AI can also be used to examine past negotiations made and as well determine the possible outcomes of the current business being made based on the decisions made in the past.

\section{Blockchain and AI technologies have also contributed to improvements in music distribution}

According to several analysts, streaming media platforms save the poorly performing music industry. Through services such as LimeWire and Napster, people became used to downloading of music tunes at free costs. However, this made record labels suffer. Streaming has it reasonable for people to pay for music again. However, numerous artists and enthusiasts are still in the dark about the associated payment models and distribution. There are a few companies that are interested in changing that (Shah
\& Jani, 2018). Among them is Volareo, a smart speaker brand that uses AI to perform numerous similar things done by the well-known smart speakers. These include playing songs asked for by people and responding to voice commands. Its ability to enable people to support their artists with the use of cryptocurrency payments distinguishes it from other speakers. With the use of this platform, people can develop stronger connections with the artists they like and as well as reward them.

\section{Blockchain and AI also facilitate online shopping}

Due to the existence of technologies such as augmented Reality and Chatbots, online shopping is considerably rising. It is not surprising why there are multiple applications for blockchain and AL to change ecommerce as well. Eligma is a platform that uses both AI and Blockchain to change how people find things to buy and track shipments. Part of this business strategy is enabling people to pay for their purchases with the use of cryptocurrencies, even if stores do not yet support them (Shah \& Jani, 2018). A blockchain system developed with Ethereum applies smart contracts to enable people to engage with potential buyers and sellers safely. Additionally, AI reveals the commodities with the best price/quality ratio and as well makes recommendations to sellers about the best time to place their goods on the market (Baruri, 2016). One of the advantages associated with blockchain is that the use of a single platform to perform multiple e-commerce increases the efficiency of buying and selling. Stores also find it easy to verify process returns and purchases since it is impossible to alter information once it is entered on the blockchain.

\section{Augmented reality has dramatically impacted Financial} and Banking services

AR technology allows users to overlay 3D models and digital information on top of the real-world environment. AR technology is a relatively immersive experience controlled by a heads up display (HUD) or existing tablets and smartphones, unlike Virtual Reality (VR), which gives a completely immersive experience to the user (Ramos, Trilles, Torres-Sospedra, \& Perales, 2018). In 2017, both Google and Apple introduced their AR development platforms, ARCore and ARKit, to the public, respectively. This move made by Google and Apple could become a game-changer, especially for financial services companies expressing interest in investigating AR capabilities (Ramos, et al., 2018). Financial institutions can now create new immersive experiences and engage their customers via millions of already existing compatible tablets and smartphones with the ongoing evolution of Google ARCore and Apple ARKit. By the end of 2018, it was estimated that financial services companies would have gained access to over one billion Android and iOS compatible mobile devices.

AR enables consumers to observe information in an engaging, concise, and immersive way. One of the biggest challenges banks face today is providing higher visibility of spending behaviors and patterns and ensuring more excellent customer choice (Ramos, et al., 2018). This is one specific area where AR can have a significant impact on enabling customers to come up with more informed 
decisions by being exposed to a new way of interpreting banking information and data. For example, AR can be used by banks to display charts and graphs that demonstrate their customers saving account performance and as well make recommendations on the ways through which customers can maximize their spending patterns (Ramos, et al., 2018).

\section{Banks can use augmented reality as a competitive differentiator}

Precisely that consumer banking was transformed by mobile technology in the past decades, AR can display an equally transformative impact in the coming years. Consumers have shifted to the use of mobile banking applications for millennials. Currently, financial institutions and banks are trying to develop strategies through which they can increase the engagement of new generation customers who are not willing to use physical branches to carry out their banking tasks. As such, banks are currently considering the use of mobile technology to enhance consumer engagement, especially the ones struggling to increase engagement of the new generation customers.

\section{CONCLUSION}

The majority of the banks are still using several inefficient manual processes, such as account reconciliations that are very costly. Precisely, operational costs and IT in the capital markets are approximated to be $\$ 100-150$ billion per annum. For a very long time, Fintech technology innovations have been identified as the best measure that can minimize such costs and as well introduce a higher automation level. Recently, BNP Paribas tested this theory and completed a pilot for fund distribution transactions on Fintech technologies. Banks dramatically benefit from a streamlined system experience applicable to all types of funds and geographies, while the investors benefit from the reduced time of transaction processing. Basing on the estimates made, the ROI of the financial technologies based on Fintech innovations for settlement of operations is very profitable.

\section{BIBLIOGRAPHY}

[1] Aazhvaar, V. (2019). ARTIFICIAL INTELLIGENCE IN INDIAN BANKING SECTOR: CHALLENGES AND OPPORTUNITIES. International Journal of Advanced Research. 7. 1581-1587. 10.21474/IJAR01/8987

[2] Baruri, P. (2016). Blockchain-Powered Financial Inclusion, a Paper Published by Cognizant

[3] Bhuvana, M., Thirumagal, PG., and Vasantha, S. (2016). Big Data Analytics - A Leveraging Technology for Indian Commercial Banks, Indian Journal of Science and Technology, Vol 9 (32)

[4] Degbelo, A., Granell, C., Trilles, S., Bhattacharya, D., Casteleyn, S., Kray, C. (2016). Opening up smart cities: Citizen-Centric challenges and opportunities from GIScience. ISPRS Int. J. GeoInf, 5, 16 .

[5] Pilkington, M. (2018). Blockchain Technology: Principles and Applications. Research Handbook on Digital Transformations, edited by F. Xavier Olleros and Majlinda Zhu. Edward Elgar.

[6] Ramos, F., Trilles OS., \& Torres-Sospedra, J., \& Perales, F. (2018). New Trends in Using Augmented Reality Apps for Smart City Contexts. ISPRS International Journal of Geo-Information. 7. 478. 10.3390/ijgi71204

[7] Shah, T., \& Jani, S. (2018). Applications of Blockchain Technology in Banking \& Finance. 10.13140/RG.2.2.35237.96489.

[8] Shivkumar, G., and Nihaal, M. (2017). A Survey on the Role of Artificial Intelligence in FinTech. International Journal of Innovative Research in Computer and Communication Engineering. Vol. 5, Issue 6, June 2017 